\title{
Intradialytic parenteral nutrition improves protein and energy homeostasis in chronic hemodialysis patients
}

\author{
Lara B. Pupim, ${ }^{1}$ Paul J. Flakoll, ${ }^{2,3}$ John R. Brouillette, ${ }^{1}$ Deanna K. Levenhagen, ${ }^{2}$ \\ Raymond M. Hakim, ${ }^{1}$ and T. Alp Ikizler ${ }^{1}$ \\ ${ }^{1}$ Department of Medicine, Division of Nephrology, \\ ${ }^{2}$ Department of Surgery, and \\ ${ }^{3}$ Department of Biochemistry, Vanderbilt University Medical Center, Nashville, Tennessee, USA
}

\begin{abstract}
Decreased dietary protein intake and hemodialysis-associated protein catabolism are among several factors that predispose chronic hemodialysis (CHD) patients to protein calorie malnutrition. Since attempts to increase protein intake by dietary counseling are usually ineffective, intradialytic parenteral nutrition (IDPN) has been proposed as a potential therapeutic approach in malnourished CHD patients. In this study, we examined protein and energy homeostasis during hemodialysis in seven CHD patients at two separate hemodialysis sessions, with and without IDPN administration. Patients were studied 2 hours before, during, and 2 hours following a hemodialysis session, using a primed constant infusion of $\mathrm{L}-\left(1-{ }^{13} \mathrm{C}\right)$ leucine and $\mathrm{L}-\left(\mathrm{ring}-{ }^{2} \mathrm{H}_{5}\right)$ phenylalanine. Our results showed that IPDN promoted a large increase in whole-body protein synthesis and a significant decrease in whole-body proteolysis, along with a significant increase in forearm muscle protein synthesis. The net result was a change from an essentially catabolic state to a highly positive protein balance, both in whole-body and forearm muscle compartments. We conclude that the provision of calories and amino acids during hemodialysis with IDPN acutely reverses the net negative whole-body and forearm muscle protein balances, demonstrating a need for long-term clinical trials evaluating IDPN in malnourished CHD patients.
\end{abstract}

J. Clin. Invest. 110:483-492 (2002). doi:10.1172/JCI200215449.

\section{Introduction}

The mortality and morbidity rate in end-stage renal disease (ESRD) patients in the United States is unacceptably high (1). Among several factors that have been identified as predictors of this poor outcome, lean-body wasting and protein calorie malnutrition (PCM) are important ones because they are potentially reversible (2).

Received for publication March 12, 2002, and accepted in revised form June 11, 2002.

Address correspondence to: $\mathrm{T}$. Alp Ikizler, Vanderbilt University Medical Center, 1161 21st Avenue South, Division of Nephrology, S-3223 Medical Center North, Nashville, Tennessee 37232-2372, USA. Phone: (615) 343-6104; Fax: (615) 343-7156; E-mail: alp.ikizler@mcmail.vanderbilt.edu.

Conflict of interest: No conflict of interest has been declared. Nonstandard abbreviations used: end-stage renal disease (ESRD); protein calorie malnutrition (PCM); chronic hemodialysis (CHD); hemodialysis (HD); amino acid (AA); intradialytic parenteral nutrition (IDPN); arteriovenous (AV); control (CTL); General Clinical Research Center (GCRC); kg fatfree mass per hour $(\mathrm{kg} \mathrm{FFM} / \mathrm{h})$; C-reactive protein (CRP); branched-chain AA (BCAA); essential AA (EAA); total AA (TAA); nonessential amino acid (NEAA); ketoisocaproate (KIC); gas chromatography/mass spectrometry (GC/MS); $N$-methyl- $N$-(tbutyldimethylsilyl)-trifluoroacetamide (MtBSTFA); tbutyldimethylchlorosilane (t-BDMCS); rate of appearance (Ra); rate of disappearance (Rd); total energy expenditure (TEE); normalized protein catabolic rate (n-PCR); dietary protein intake (DPI).
Factors that predispose ESRD patients on chronic hemodialysis (CHD) therapy to PCM are multiple and include several nondialysis and dialysis-related factors (3-5). Among these factors, decreased dietary protein and calorie intake and the hemodialysis-associated catabolism are important contributors. Several studies have highlighted the inadequate level of dietary intake in CHD patients (6-8). Furthermore, the hemodialysis (HD) procedure is associated with loss of substantial amounts of amino acids (AA) in the dialysate and decreased plasma AA concentrations, accelerated rates of whole-body and skeletal muscle proteolysis, and increased energy expenditure, resulting in net negative intradialytic protein and energy balance $(9,10)$. These metabolic derangements also impact protein and energy balance after the HD procedure is finished (9). The combination of these factors may be an important cause of muscle wasting and PCM observed in CHD patients.

Several approaches have been proposed as potential therapeutic interventions for the treatment of malnourished CHD patients. A number of reports have emphasized the effectiveness of intradialytic parenteral nutrition (IDPN) (11-13). In particular, IDPN is a convenient and safe therapeutic intervention that provides nutrition during the HD procedure. However, not all studies have shown clear-cut benefits for IDPN, and 


\section{Table 1}

Demographic, nutritional characteristics, and biochemical parameters of the study population $(n=7)$

\section{Demographics \\ Gender (M/F) \\ Race (Caucasian/African American) \\ Age (years) \\ Etiology of ESRD (\%)}

\section{Body composition}

Body weight $(\mathrm{kg})$

Body mass index $\left(\mathrm{kg} / \mathrm{cm}^{2}\right)$

Fat mass by DEXA (\%)

Baseline biochemistries

Serum albumin $(\mathrm{g} / \mathrm{dl})$

Serum prealbumin $(\mathrm{mg} / \mathrm{dl})$

Serum transferrin $(\mathrm{mg} / \mathrm{dl})$

Serum cholesterol $(\mathrm{mg} / \mathrm{dl})$

Total $\mathrm{CO}_{2}(\mathrm{mg} / \mathrm{dl})$

$\mathrm{CRP}(\mathrm{mg} / \mathrm{dl})$

Hematocrit (\%)

n-PCR (g/kg/day)

$$
\begin{gathered}
5(71 \%) / 2(29 \%) \\
1(14 \%) / 6(86 \%) \\
46.57 \pm 19.44 \\
4(57 \%) \text { hypertension } \\
2(29 \%) \text { ADPKD } \\
1(14 \%) \text { glomerulonephritis }
\end{gathered}
$$

$$
\begin{aligned}
& 73.49 \pm 14.89 \\
& 25.41 \pm 4.14 \\
& 27.26 \pm 8.99
\end{aligned}
$$

Control

$4.24 \pm 0.3$

$43.7 \pm 8.0$

$189 \pm 37$

$187 \pm 27$

$22.3 \pm 1.9$

$0.74 \pm 0.4$

$38.7 \pm 2.2$

$0.97 \pm 0.14$ minutes, and $\mathrm{V}$ is the volume of distribution of urea in the body in $\mathrm{ml}$ ), on a thrice weekly HD program. Patients with active infectious or inflammatory disease (i.e., vascular access infections and overt periodontal disease), patients hospitalized within 3 months prior to the study, patients with recirculation in the vascular access and/or vascular access blood flow less than $750 \mathrm{ml} / \mathrm{min}$ detected on the arteriovenous (AV) shunt, and those receiving steroids and/or immunosuppressive agents were excluded from the study. The Institutional Review Board of Vanderbilt University approved the study protocol, and written informed consent was obtained from all study patients. Patient characteristics are shown in Table 1.

Design. This was a randomized crossover study. After reviewing the inclusion and exclusion criteria, eligible patients were randomly assigned to either IDPN or control (CTL) as a first protocol, using simple randomization. All patients who participated in this study were crossed over and participated in both protocols, with at least 4 weeks between each. Within a week prior to each study, dual-energy $x$-ray absorptiometry was performed to estimate lean and fat body masses, and resting metabolic rate was measured by indirect calorimetry to establish energy requirements prior to experimentation.

The patients were admitted to the General Clinical Research Center (GCRC) at Vanderbilt University Medical Center the day before the study at approximately 7:00 p.m., received a meal from the GCRC bionutrition services upon admission, and remained fasting after that. The last meal was given at least 10 hours prior to the initiation of the study for all patients and consisted of $18 \%$ protein and 30\% lipids. Energy intake was kept at maintenance levels based on the Harris-Benedict equation, and each subject's sex, height, weight, and activity levels.

A schematic diagram of the metabolic study-day protocol is depicted in Figure 1. Each metabolic study consisted of a pre-HD phase (a 2-hour equilibration phase followed by a 0.5 -hour basal-sampling phase), a 4-hour dialysis phase, and a 2 -hour post-HD phase. In the protocol using IDPN, its administration was started 30 minutes after dialysis initiation and continued through the end of dialysis. Constant infusion of isotopes continued throughout the study. Simultaneous blood and breath samples were collected once prior to the start of the study, three times during the basal-sampling phase, six times during IDPN and dialysis, and three times during the postdialysis phase.

A dialysis needle was placed at the venous site of the AV shunt of the forearm at 6:00 a.m. to collect a baseline blood sample (to assess baseline biochemical nutritional markers and isotopic backgrounds) and then to initiate the isotope infusion. An AV shunt is commonly used for the vascular access with HD, which is created by connecting an artery to a nearby vein either by direct surgical anastomosis of the native vessels (fistula) or with an artificial synthetic vascular 
material (graft). In this study, two patients had a native fistula and five patients had an artificial graft. The arterial side of the AV shunt was the site of choice used for sampling arterial blood. The only occasion that would affect the arterial purity of the samples would be if there were stenoses in the AV shunt causing the venous blood to mix with arterial blood (recirculation). Therefore, recirculation of the AV shunt as well as vascular access blood flow to assess stenoses in the AV shunts was checked in every patient prior to study using ultrasound dilution technique (Transonic Systems Inc., Ithaca, New York, USA). Arterial vascular access obtained though the arterial side of the AV shunt was used to perform HD and to sample arterial blood. The venous site of the AV shunt was used to infuse the isotopes. Another catheter was placed in a deep vein (on a retrograde insertion) of the contralateral forearm to sample blood draining the forearm muscle bed. At the start of the infusion, subjects received a bolus injection of $\mathrm{NaH}^{13} \mathrm{CO}_{3}(0.12 \mathrm{mg} / \mathrm{kg})$, $\mathrm{L}-\left(1-{ }^{13} \mathrm{C}\right)$ leucine $(7.2 \mu \mathrm{mol} / \mathrm{kg})$ and $\mathrm{L}-\left(\mathrm{ring}-{ }^{2} \mathrm{H}_{5}\right)$ phenylalanine $(7.2 \mu \mathrm{mol} / \mathrm{kg})$ to prime the $\mathrm{CO}_{2}$, leucine, and phenylalanine pools, respectively. A continuous infusion of leucine $(0.12 \mu \mathrm{mol} / \mathrm{kg} / \mathrm{min})$ and phenylalanine $(0.12 \mu \mathrm{mol} / \mathrm{kg} / \mathrm{min})$ isotopes was then started and continued throughout the remainder of the study.

Patients were dialyzed for 4 hours with blood flow of $400 \mathrm{ml} / \mathrm{min}$ and dialysate flow of $500 \mathrm{ml} / \mathrm{min}$. Ultrafiltration rates were determined by the patients' needs and "estimated dry weight" and were similar during both studies. The composition of the dialysate used during the study was identical for all treatments and consisted of sodium $139 \mathrm{mEq} / \mathrm{l}$, potassium 2 $\mathrm{mEq} / \mathrm{l}$, calcium $2.5 \mathrm{mEq} / \mathrm{l}$, glucose $200 \mathrm{mg} / \mathrm{dl}$, and bicarbonate $39 \mathrm{mEq} / \mathrm{l}$.

When IDPN was used, its infusion was started 30 minutes after initiation of HD via the venous port of the bubble trap on the HD tubing and continued throughout the entire HD procedure (total of 3.5 hours of IDPN infusion). The IDPN treatment was based upon existing recommendations (15). The solution was given at a rate of $150 \mathrm{ml} / \mathrm{h}$ and consisted of $300 \mathrm{ml}$ of AAs at a concentration of $15 \%, 150 \mathrm{ml}$ of dextrose at a concentration of $50 \%$, and $150 \mathrm{ml}$ of lipids at a concentration of $20 \%$. AA solution (15\% Clinisol; Baxter Healthcare Corp., Deerfield, Illinois, USA) consisted of nine essential AAs (lysine, $1.18 \mathrm{~g}$; leucine, $1.04 \mathrm{~g}$; phenylalanine, $1.04 \mathrm{~g}$; valine, $960 \mathrm{mg}$; histidine, $894 \mathrm{mg}$; isoleucine, $749 \mathrm{mg}$; methionine, $749 \mathrm{mg}$; threonine, $749 \mathrm{mg}$; thryptophan, $250 \mathrm{mg}$ ) and eight nonessential AAs (alanine, $2.17 \mathrm{~g}$; arginine, $1.47 \mathrm{~g}$; glycine, $1.04 \mathrm{~g}$; proline, $894 \mathrm{mg}$; glutamate, $749 \mathrm{mg}$; serine, $592 \mathrm{mg}$; aspartate, $434 \mathrm{mg}$; tyrosine, $39 \mathrm{mg}$ ). This solution provided $188 \mathrm{kcal} / \mathrm{h}$ or $3.5 \mathrm{kcal} / \mathrm{kg}$ fat-free mass per hour ( $\mathrm{kg} \mathrm{FFM} / \mathrm{h})$. The extra volume, as well as electrolytes, that IDPN provided to the patients was accounted for and removed during HD. Once HD was finished, dialysis lines were disconnected and the 2-hour post-HD phase ensued. After the post-HD phase, all needles were

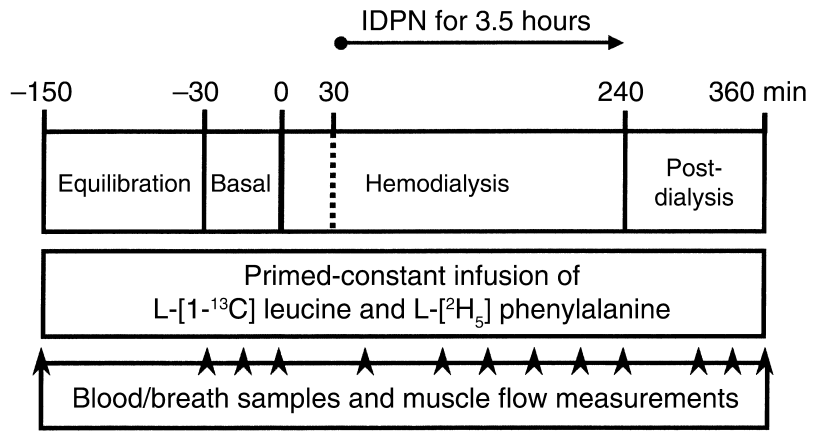

Figure 1

Schematic diagram of the metabolic study-day protocol. Arrowheads denote time points for blood draws, breath sample collections, and muscle plasma flow measurements. A primed-constant infusion of $\mathrm{L}-\left(1-{ }^{13} \mathrm{C}\right)$ leucine and $\mathrm{L}-\left(\right.$ ring $\left.-{ }^{2} \mathrm{H}_{5}\right)$ phenylalanine was maintained throughout the entire study (360 minutes).

removed, and the patients were given a meal and observed at the GCRC until stable, after which they were discharged. Patients continued their CHD therapy at the outpatient unit as scheduled.

Simultaneously with each blood sampling, breath samples were collected from the subjects using a Douglas bag with duplicate $20-\mathrm{ml}$ samples placed into nonsiliconized glass vacutainer tubes for measurement of breath ${ }^{13} \mathrm{CO}_{2}$ enrichment. Subjects were asked to breathe through a mask for 1 minute each time blood was collected. In addition, forearm blood flow was estimated using capacitance plethysmography (Model 2560 with URI/CP software v 3.0; UFI, Morro Bay, California, USA). Simultaneous energy expenditure and respiratory quotient were determined by indirect calorimetry using a Sensormedics 2900 metabolic cart (Sensormedics, Palo Alto, California, USA) to measure ventilation rates, $\mathrm{CO}_{2}$ production, and $\mathrm{O}_{2}$ consumption.

Analytical procedures. Blood samples were collected into Venoject tubes containing $15 \mathrm{mg} \mathrm{Na} \mathrm{NaDTA}_{2}$ (Terumo Medical Corp, Elkton, Maryland, USA). A 3-ml aliquot of blood was transferred to a tube containing EDTA and reduced glutathione with the plasma stored at $-80^{\circ} \mathrm{C}$ for later measurement of plasma epinephrine and norepinephrine concentrations by HPLC (16). The remaining blood was spun in a refrigerated $\left(4^{\circ} \mathrm{C}\right)$ centrifuge (Beckman Instruments Inc., Fullerton, California, USA) at $2,000 \mathrm{~g}$ for 10 minutes, and plasma was extracted and stored at $-80^{\circ} \mathrm{C}$ for later analysis. Plasma glucose concentrations were determined by the glucose oxidase method (Model II glucose analyzer; Beckman Instruments Inc.).

Nutritional biochemical parameters were done at a specialized ESRD clinical and special chemistry laboratory (Spectra Laboratories, San Juan, California, USA). Serum albumin was analyzed using bromcresol green technique. Serum prealbumin was analyzed by an antigen-Ab complex assay, and serum transferrin was analyzed by turbidimetric reading (Hitachi 717; Boehringer 


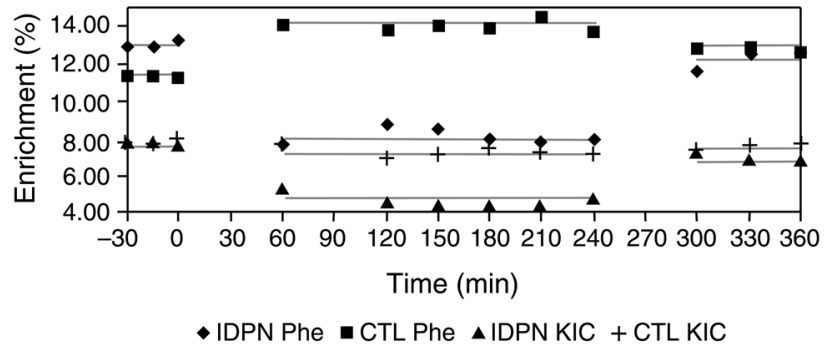

Figure 2

Plasma enrichment of phenylalanine (Phe) and $\mathrm{KIC}$ comparing $\mathrm{CTL}$ and IDPN. Diamonds denote phenylalanine enrichment during IDPN protocol, squares denote phenylalanine enrichment during CTL protocol, triangles denote $\mathrm{KIC}$ enrichment during IDPN protocol, and plus sign denotes $\mathrm{KIC}$ enrichment during CTL protocol.

Mannheim Biochemicals Inc., Indianapolis, Indiana, USA). C-reactive protein (CRP) was measured using nephelometric analysis at the Vanderbilt University Medical Center clinical chemistry laboratory.

Immunoreactive insulin was determined in plasma with a double-Ab system. Plasma aliquots for glucagon determination were placed in tubes containing 25 kallikrein-inhibitor units of aprotinin (Trasylol; FBA Pharmaceutical, New York, New York, USA) and were later measured by established radioimmunoassay with a double-Ab system modified from the method of Morgan and Lazarow (17) for insulin. Insulin and glucagon antisera and standards, as well as ${ }^{125} \mathrm{I}$-labeled hormones, were obtained from R.L. Gingerich (Linco Research Inc., St. Louis, Missouri, USA). Clinical Assays Gammacoat Radioimmunoassay Kit (TravenolGenTech, Cambridge, Massachusetts, USA) was used to measure plasma cortisol concentrations. Plasma IGF-I concentrations were determined by a radioimmunoassay acid-extraction procedure (Nichols Institute Diagnostics, San Juan Capistrano, California, USA). Plasma AA concentrations were determined by reversed-phase high-performance liquid chromatography after derivatization with phenylisothiocynate (18). Individual AAs were also placed into groups for analysis. These groups included branched-chain AAs (BCAAs; the sum of leucine, isoleucine, and valine); essential AAs (EAAs; the sum of arginine, histidine, isoleucine, leucine, lysine, methionine, phenylalanine, theonine, tryptophan, and valine); total AAs (TAA; the sum of all individual AAs); and nonessential AAs (NEAAs: the difference between TAA and EAA).

Plasma enrichments of $\left({ }^{13} \mathrm{C}\right)$ leucine $\left({ }^{13} \mathrm{C}\right)$ ketoisocaproate (KIC), and $\left(\right.$ ring $\left.^{2}{ }^{2} \mathrm{H}_{5}\right)$ phenylalanine were determined using gas chromatography/mass spectrometry (GC/MS) (Hewlett-Packard 5890a GC and 5970 MS; Hewlett-Packard, San Fernando, California, USA). Plasma was deproteinized with $4 \%$ perchloric acid, and the supernatant was passed over a cationexchange resin to separate the keto acids and AAs. The keto acids were further extracted with methylene chloride and $0.5 \mathrm{M}$ ammonium hydroxide (19). After drying under nitrogen gas, keto acid and AA fractions were derived (20) with $N$-methyl- $N$-(t-butyldimethylsilyl)-trifluoroacetamide (MtBSTFA) containing 1\% t-butyldimethylchlorosilane (t-BDMCS) (Regis Technologies Inc., Morton Grove, Illinois, USA). The derived samples were then analyzed with GC/MS for plasma leucine, phenylalanine, and KIC enrichments using selected ion monitoring. The major fragments analyzed for the tBDMS derivative of $\mathrm{KIC}$ and $\left({ }^{13} \mathrm{C}\right) \mathrm{KIC}$ were the (M-57) ion fragments $301 \mathrm{~m} / z$ and $302 \mathrm{~m} / z$, respectively. The enrichment was quantified in plasma as the ratio of $\left({ }^{13} \mathrm{C}\right.$ ) KIC:KIC (ion abundance of $301 / 302 \mathrm{~m} / z$ ). Enrichment measurements were made in duplicate, and duplicates had a coefficient of variation less than $3 \%$. Breath ${ }^{13} \mathrm{CO}_{2}$ was measured by isotope ratio mass spectrometry (Metabolic Solutions Inc., Nashua, New Hampshire, USA) (21).

Calculations. Net skeletal muscle protein balance (synthesis-breakdown) was determined by dilution and enrichment of phenylalanine across the forearm as described by Gelfand and Barrett (22). Because phenylalanine is neither synthesized de novo nor metabolized by skeletal muscle, rate of appearance $(\mathrm{Ra})$ of unlabeled phenylalanine reflects muscle protein breakdown, whereas the rate of disappearance (Rd) of labeled phenylalanine estimates muscle protein synthesis (22). Phenylalanine Rd was calculated by multiplying the fractional extraction of the labeled phenylalanine (based on plasma arterial and venous phenylalanine enrichments and concentrations) by the arterial phenylalanine concentration and normalized to forearm blood flow measured by plethysmography (expressed as $100 \mathrm{ml} / \mathrm{min}$ ). Net phenylalanine Ra was calculated by subtracting the net $\mathrm{AV}$ balance of phenylalanine across the extremity from the phenylalanine Rd (22, 23). Rates of skeletal muscle protein breakdown and net synthesis were determined from the phenylalanine $\mathrm{Rd}$ and $\mathrm{Ra}$, assuming that $3.8 \%$ of skeletal muscle protein is comprised of phenylalanine.

The steady-state rates of total whole-body leucine appearance $(\mathrm{Ra})$ were calculated by dividing the $\left({ }^{13} \mathrm{C}\right)$ leucine infusion rate by the plasma $\left({ }^{13} \mathrm{C}\right) \mathrm{KIC}$ enrichment (23). Plasma KIC provides a better estimate of intracellular leucine enrichment than does plasma leucine enrichment due to the fact that KIC is derived from intracellular leucine metabolism (23). Steadystate conditions for $\mathrm{KIC}$ and $\mathrm{CO}_{2}$ enrichments were achieved as evidenced by slopes within each phase not significantly different from zero (Figure 2). Endogenous leucine $\mathrm{Ra}$ (an estimate of whole-body protein breakdown) was determined by subtracting the rate of leucine infusion via the IDPN from the total Ra (expressed as milligram per kilogram of FFM per minute). Breath ${ }^{13} \mathrm{CO}_{2}$ production was determined by multiplying the total $\mathrm{CO}_{2}$ production rate by the breath ${ }^{13} \mathrm{CO}_{2}$ enrichment (23). The rate of whole-body leucine oxidation was calculated by dividing breath ${ }^{13} \mathrm{CO}_{2}$ production by 0.8 (correction factor for the retention of ${ }^{13} \mathrm{CO}_{2}$ in the bicarbonate pool) (24) and by the plasma KIC enrichment. Leucine Rd during the 
dialysis phase was corrected for leucine loss into the ultrafiltration volume by measuring the ultrafiltration volume and the leucine concentration in the dialysate and by subtracting the leucine lost in the dialysate from the total $\mathrm{Ra}$. The nonoxidative leucine $\mathrm{Rd}$, an estimate of whole-body protein synthesis, was determined indirectly by subtracting leucine oxidation from corrected total leucine $\mathrm{Rd}$. Rates of whole-body protein breakdown, AA oxidation, and protein synthesis were calculated from the endogenous leucine $\mathrm{Ra}$, the leucine oxidation rate, and the nonoxidative leucine $\mathrm{Rd}$, respectively, assuming that $7.8 \%$ of whole-body protein is comprised of leucine (25).

Rates of whole-body AA, carbohydrate, and lipid oxidation were determined from indirect calorimetry in combination with the leucine oxidation data. The energy expended due to AA oxidation was subtracted from the total energy expenditure (TEE), and the net rates of carbohydrate and lipid oxidation were calculated based on the nonprotein respiratory quotient (26). Energy balance was determined by subtracting TEE from energy intake. Nutrient balance was determined by subtracting nutrient oxidation from nutrient intake. The assumptions and limitations of calculating net substrate oxidation based on indirect calorimetry measurements have been reviewed previously (26).

Statistical analysis. For each protocol, mean variables for each phase (before, during, and after HD) were calculated as the average of the time points for each phase. Values presented in the text and figures are means plus or minus SEM. For comparisons between study protocols (IDPN vs. CTL), a paired $t$ test was used for parametric distribution and a Wilcoxon signed-rank test for nonparametric distribution. Differences between the mean values within phases (before, during, and after HD) were assessed using a repeated-measures ANOVA (Statistical Analysis System for Windows, 1996, Release
6.12; SAS Institute Inc., Cary, North Carolina, USA). A $P$ value of less than 0.05 was required to reject the null hypothesis of no difference between the means.

\section{Results}

Blood chemistries. Table 1 depicts baseline biochemical nutritional markers, including serum albumin, serum prealbumin, serum transferrin, and serum cholesterol, as well as $\mathrm{CO}_{2}$ and CRP for the two study protocols: control and IDPN. As can be seen, these measurements were similar between CTL and IDPN protocols, and there were no statistical differences. As implied by the above-mentioned biochemical markers, the population studied was in an overall adequately nourished status and not inflamed. Normalized protein catabolic rate (n-PCR), an estimation of dietary protein intake, ranged from 0.97 to $1.28 \mathrm{~g} / \mathrm{kg} /$ day and was on average $0.97 \pm 0.14 \mathrm{~g} / \mathrm{kg} /$ day and $1.00 \pm 0.17 \mathrm{~g} / \mathrm{kg} /$ day within a week of CTL and IDPN study protocols, respectively. Measurement of pre- and post-HD blood chemistries, including blood urea nitrogen, showed expected changes following HD treatment without any significant difference between the two separate HD sessions within patients.

Metabolic parameters. Table 2 shows the results for plasma metabolic hormones and glucose concentrations for the two study protocols. Insulin concentrations were significantly higher during IDPN administration compared with CTL (approximately fourfold, $P<0.05)$. The difference in insulin levels was still significant during the post-HD phase, albeit to a smaller extent. The other metabolic hormones did not show statistically or numerically significant differences between IDPN and CTL sessions. Plasma glucose levels increased significantly during HD in both study protocols. Glucose concentrations were significantly higher during IDPN administration compared

Table 2

Metabolic hormones and glucose concentrations

\begin{tabular}{|c|c|c|c|c|}
\hline & & Before HD & During HD & After HD \\
\hline Insulin $(\mu \mathrm{U} / \mathrm{ml})$ & $\begin{array}{l}C T L \\
\text { IDPN }\end{array}$ & $\begin{array}{l}7.8 \pm 1.5 \\
7.1 \pm 1.1\end{array}$ & $\begin{array}{l}13.1 \pm 1.8 \\
48.9 \pm 11.3^{\mathrm{A}}\end{array}$ & $\begin{array}{c}7.7 \pm 1.2 \\
11.3 \pm 1.4^{\mathrm{A}}\end{array}$ \\
\hline Growth hormone (ng/ml) & $\begin{array}{l}\text { CTL } \\
\text { IDPN }\end{array}$ & $\begin{array}{l}1.18 \pm 0.68 \\
0.92 \pm 0.29\end{array}$ & $\begin{array}{l}0.32 \pm 0.07 \\
0.74 \pm 0.43\end{array}$ & $\begin{array}{l}0.78 \pm 0.21 \\
0.87 \pm 0.29\end{array}$ \\
\hline IGF-1 (ng/ml) & $\begin{array}{l}\text { CTL } \\
\text { IDPN }\end{array}$ & $\begin{array}{l}296 \pm 82 \\
269 \pm 82\end{array}$ & $\begin{array}{l}307 \pm 15 \\
242 \pm 70\end{array}$ & $\begin{array}{l}296 \pm 28 \\
237 \pm 49\end{array}$ \\
\hline Cortisol $(\mu \mathrm{g} / \mathrm{I})$ & $\begin{array}{l}C T L \\
\text { IDPN }\end{array}$ & $\begin{array}{l}14.0 \pm 3.1 \\
13.8 \pm 3.2\end{array}$ & $\begin{array}{l}11.9 \pm 1.5 \\
13.9 \pm 2.8\end{array}$ & $\begin{array}{l}11.0 \pm 2.2 \\
13.9 \pm 1.7\end{array}$ \\
\hline Epinephrine (pg/ml) & $\begin{array}{l}C T L \\
\text { IDPN }\end{array}$ & $\begin{array}{l}62 \pm 8 \\
44 \pm 4\end{array}$ & $\begin{array}{l}36 \pm 8 \\
35 \pm 6\end{array}$ & $\begin{array}{r}64 \pm 13 \\
134 \pm 24\end{array}$ \\
\hline Norepinephrine (pg/ml) & $\begin{array}{l}C T L \\
\text { IDPN }\end{array}$ & $\begin{array}{l}743 \pm 224 \\
389 \pm 71\end{array}$ & $\begin{array}{l}508 \pm 103 \\
342 \pm 62\end{array}$ & $\begin{array}{l}605 \pm 131 \\
364 \pm 53\end{array}$ \\
\hline Plasma glucose (mg/dl) & $\begin{array}{l}\text { CTL } \\
\text { IDPN }\end{array}$ & $\begin{array}{l}82.4 \pm 2.7 \\
77.1 \pm 4.8\end{array}$ & $\begin{array}{l}113.7 \pm 3.8 \\
143.6 \pm 8.3^{\mathrm{A}}\end{array}$ & $\begin{array}{l}79.7 \pm 3.4 \\
68.1 \pm 4.8^{A}\end{array}$ \\
\hline Forearm plasma flow (ml/100 ml/min) & $\begin{array}{l}\text { CTL } \\
\text { IDPN }\end{array}$ & $\begin{array}{l}3.1 \pm 0.6 \\
2.7 \pm 0.5\end{array}$ & $\begin{array}{l}4.5 \pm 0.3 \\
2.4 \pm 0.2^{\mathrm{A}}\end{array}$ & $\begin{array}{l}3.0 \pm 0.4 \\
2.7 \pm 0.1\end{array}$ \\
\hline Forearm net glucose balance $(\mu \mathrm{g} / 100 \mathrm{ml} / \mathrm{min})$ & $\begin{array}{l}C T L \\
\text { IDPN }\end{array}$ & $\begin{array}{r}84 \pm 21 \\
128 \pm 34\end{array}$ & $\begin{array}{l}190 \pm 30 \\
209 \pm 54\end{array}$ & $\begin{array}{c}61 \pm 13 \\
120 \pm 30^{A}\end{array}$ \\
\hline
\end{tabular}

Values reported are the mean \pm SEM. ${ }^{A}$ Significant difference between CTL and IDPN $(P<0.05)$. 


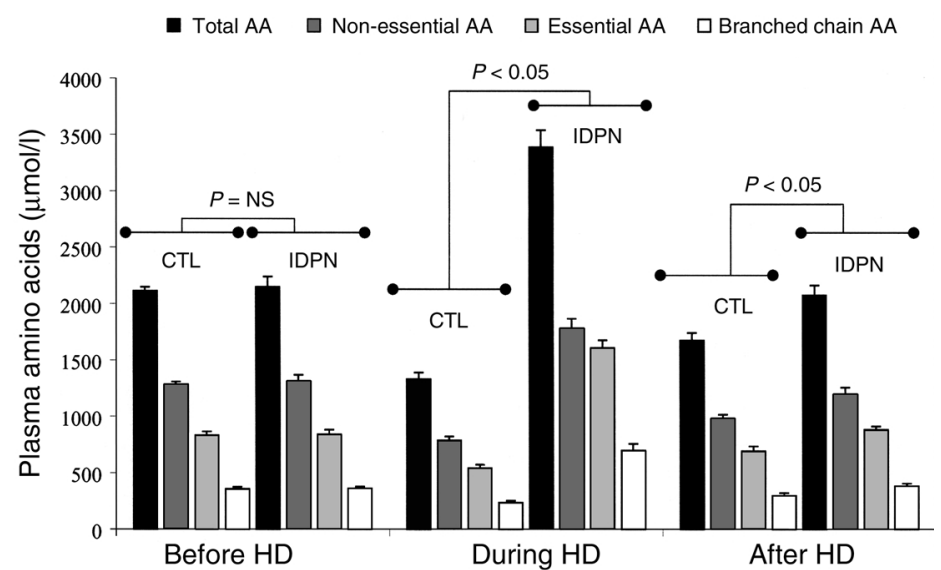

Figure 3

Plasma AA concentrations over the study period, comparing CTL and treatment (IDPN) protocols. Units are micromoles per liter.

with CTL (26\%). Forearm net glucose balance was increased similarly in both study protocols during HD. However, in the post-HD phase the forearm net glucose balance was twofold greater in the IDPN study protocol compared with CTL.

Plasma AAs and forearm AAs balance. The arterial plasma AA concentrations during the studies are graphed in Figure 3 by groups (TAA, NEAA, EAA, BCAA). During $\mathrm{HD}$ without nutritional supplementation, the plasma concentration of all individual AAs decreased substantially, consistent with our data published previously $(4,9)$. On the other hand, IDPN administration resulted in significant increases in the concentrations of all groups. Overall, during HD with IDPN, the TAAs were 2.5 -fold, EAAs were threefold, NEAAs were twofold, and BCAAs were threefold higher than during CTL. In the post-HD phase, plasma AA concentrations returned toward baseline values for most individual AAs in both study protocols. However, the plasma AA concentrations were still significantly higher in the IDPN protocol compared with CTL during the 2-hour post-HD phase.

Net forearm AA balances during HD are depicted in Figure 4. During HD, IDPN either reduced the release or increased the uptake of all groups of AAs. Therefore, treatment with IDPN resulted in a significant increase in the forearm uptake for all groups of AAs, demonstrating a highly positive net balance, compared with a net negative balance (increased release) during the CTL protocol. During the post-HD phase (with the completion of IDPN treatment), forearm AA uptake reverted back to baseline levels (data not shown), and there were no significant differences between protocols.

Whole-body protein metabolism. Table 3 depicts the results for whole-body protein metabolism components. Administration of IDPN resulted in large improvements on both proteolysis and protein synthesis. Specifically, whole-body protein synthesis was twofold higher during IDPN administration compared with CTL. Also, proteolysis was 50\% lower during IDPN compared with CTL
(Figure 5). Based on the improvements in protein synthesis and proteolysis, the net result of IDPN administration was a reversal of an essentially catabolic state observed during HD to a substantial anabolic state $(-0.98 \pm 0.10$ to $3.58 \pm 0.48$ $\mathrm{mg} / \mathrm{kg} \mathrm{FFM} / \mathrm{min} ; P<0.05)$. Of note, the improvement in whole-body protein synthesis, proteolysis, and net balance was evident for each study patient (data not shown).

Forearm muscle protein metabolism. Table 3 depicts the results for forearm protein metabolism components. The treatment with IDPN provided significantly higher forearm muscle protein synthesis during dialysis compared with CTL (3.5-fold). Forearm muscle proteolysis was not statistically significantly different between the study protocols. The net result in forearm protein balance was a change from negative (catabolism) to positive (anabolism) protein balance during IDPN administration $(-45 \pm 15$ to $53 \pm 17 \mu \mathrm{g} / 100 \mathrm{ml} / \mathrm{min} ; P<0.05)$. Forearm phenylalanine fractional extraction was not different between study protocols.

Energy metabolism and substrate oxidation. Table 4 shows the components of energy metabolism and substrate oxidation. There was no difference in the changes observed in TEE and respiratory quotient between CTL and IDPN. The rates and proportions of carbohydrate and lipid oxidation were not different either between CTL and IDPN. However, AA oxidation was significantly higher during HD with IDPN. During the postdialysis phase, differences in oxidation variables between CTL and IDPN were not significant. Overall, energy balance was positive and significantly greater with IDPN during HD. AA, carbohydrate, and lipid balances were positive and significantly greater with IDPN during HD.

- TAA INEAA $\square$ EAA $\square B C A A$

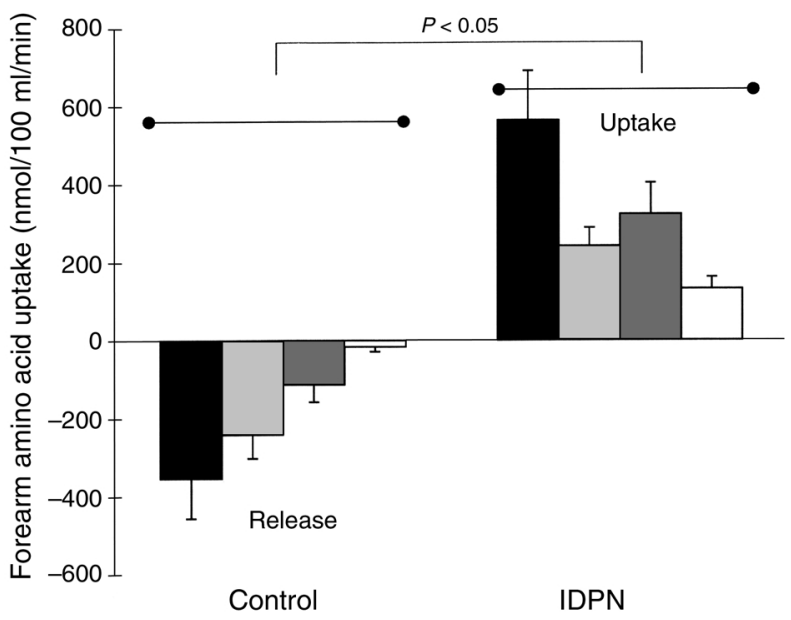

Figure 4

Forearm balance of AAs (by groups) during HD comparing CTL and IDPN. Units are nanomoles per $100 \mathrm{ml}$ per minute. 
Table 3

Components of whole body and forearm muscle protein metabolism

\begin{tabular}{|c|c|c|c|c|}
\hline & & Before HD & During HD & After HD \\
\hline \multirow[t]{2}{*}{ WB protein synthesis $(\mathrm{mg} / \mathrm{kg} \mathrm{FFM} / \mathrm{min})$} & CTL & $2.88 \pm 0.24$ & $\begin{array}{c}2.78 \pm 0.15 \\
(-0.10 \pm 0.13)\end{array}$ & $\begin{array}{c}3.01 \pm 0.22 \\
(0.13 \pm 0.14)\end{array}$ \\
\hline & IDPN & $3.09 \pm 0.35$ & $\begin{array}{r}5.45 \pm 0.38^{A} \\
(2.36 \pm 0.40)\end{array}$ & $\begin{array}{c}3.44 \pm 0.34 \\
(0.36 \pm 0.27)\end{array}$ \\
\hline \multirow[t]{2}{*}{ WB proteolysis (mg/kg FFM/min) } & CTL & $3.42 \pm 0.18$ & $\begin{array}{c}3.76 \pm 0.11 \\
(0.34 \pm 0.09)\end{array}$ & $\begin{array}{c}3.66 \pm 0.17 \\
(0.24 \pm 0.15)\end{array}$ \\
\hline & IDPN & $3.66 \pm 0.31$ & $\begin{array}{r}1.87 \pm 0.61^{\mathrm{A}} \\
(-1.79 \pm 0.48)\end{array}$ & $\begin{array}{c}4.33 \pm 0.38 \\
(0.68 \pm 0.29)\end{array}$ \\
\hline \multirow[t]{2}{*}{ Net WB protein balance $(\mathrm{mg} / \mathrm{kg} \mathrm{FFM} / \mathrm{min})$} & CTL & $-0.54 \pm 0.10$ & $-0.98 \pm 0.10$ & $-0.65 \pm 0.13$ \\
\hline & IDPN & $-0.57 \pm 0.07$ & $3.58 \pm 0.48^{\mathrm{A}}$ & $-0.89 \pm 0.06$ \\
\hline \multirow[t]{2}{*}{ FM protein synthesis $(\mu \mathrm{g} / 100 \mathrm{ml} / \mathrm{min})$} & $C T L$ & $41 \pm 8$ & $\begin{array}{c}76 \pm 20 \\
(35 \pm 24)\end{array}$ & $\begin{array}{c}78 \pm 14 \\
(37 \pm 15)\end{array}$ \\
\hline & IDPN & $66 \pm 20$ & $\begin{array}{r}275 \pm 81^{A} \\
(209 \pm 79)\end{array}$ & $\begin{array}{r}202 \pm 57^{A} \\
(136 \pm 65)\end{array}$ \\
\hline \multirow[t]{2}{*}{ FM proteolysis $(\mu \mathrm{g} / 100 \mathrm{ml} / \mathrm{min})$} & CTL & $62 \pm 13$ & $\begin{array}{l}122 \pm 24 \\
(60 \pm 27)\end{array}$ & $\begin{array}{l}105 \pm 20 \\
(43 \pm 25)\end{array}$ \\
\hline & IDPN & $80 \pm 16$ & $\begin{array}{c}222 \pm 66 \\
(142 \pm 63)\end{array}$ & $\begin{array}{c}205 \pm 67 \\
(125 \pm 68)\end{array}$ \\
\hline \multirow[t]{2}{*}{ Net FM protein balance $(\mu \mathrm{g} / 100 \mathrm{ml} / \mathrm{min})$} & CTL & $-22 \pm 6$ & $-45 \pm 15$ & $-27 \pm 13$ \\
\hline & IDPN & $-15 \pm 7$ & $53 \pm 17^{A}$ & $-3 \pm 32$ \\
\hline \multirow[t]{2}{*}{ FM phenylalanine fractional extraction (\%) } & $C T L$ & $8.0 \pm 2$ & $18 \pm 5$ & $21 \pm 6$ \\
\hline & IDPN & $12 \pm 3$ & $22 \pm 3$ & $23 \pm 3$ \\
\hline
\end{tabular}

Values reported are the mean \pm SEM. Values in parentheses represent the mean $( \pm S E M)$ of the change from the pre-HD phase. ${ }^{A}$ Significant difference between CTL and IDPN $(P<0.05)$. WB, whole-body; FM, forearm muscle.

\section{Discussion}

Several studies have emphasized the importance of protein-calorie malnutrition (PCM) on clinical outcome in ESRD patients, particularly in patients on CHD. Based on these reports, attempts have been made to treat PCM in malnourished CHD patients by different strategies, including encouragement of oral nutrition and intradialytic nutritional supplementation. In this study, we provide evidence that parenteral nutritional supplementation administered during HD results in robust improvements in protein and energy metabolism in CHD patients, based on precise stable isotope infusion techniques.

Many studies have documented the importance of inadequate dietary protein intake (DPI) in CHD patients. Inadequate DPI is related to multiple factors, including anorectic effects of advanced uremia, dialysis-related factors, use of multiple medications, frequent hospitalizations, and certain comorbid conditions such as insulin-dependent diabetes mellitus and gastrointestinal disturbances $(3,27,28)$. A recent study by Kaysen et al. demonstrated the importance of DPI as a determinant of serum albumin concentrations, an important nutritional marker in CHD patients (29). In addition to inadequate DPI as a cause of decreased anabolism, the HD procedure further exacerbates the negative nitrogen balance in CHD patients. The HD procedure induces increased whole-body proteolysis above and beyond what would be expected due to the AA losses into the dialysate. Importantly, this catabolic event is not accompanied by a compensatory increase in protein synthesis (9).
It is, therefore, crucial to develop strategies to improve dietary nutrient intake in $\mathrm{CHD}$ patients. In addition to certain preventive measures, such as an increase in the dialysis dose and use of biocompatible membrane, attempts have been made to increase DPI by dietary counseling. Unfortunately, dietary counseling is not

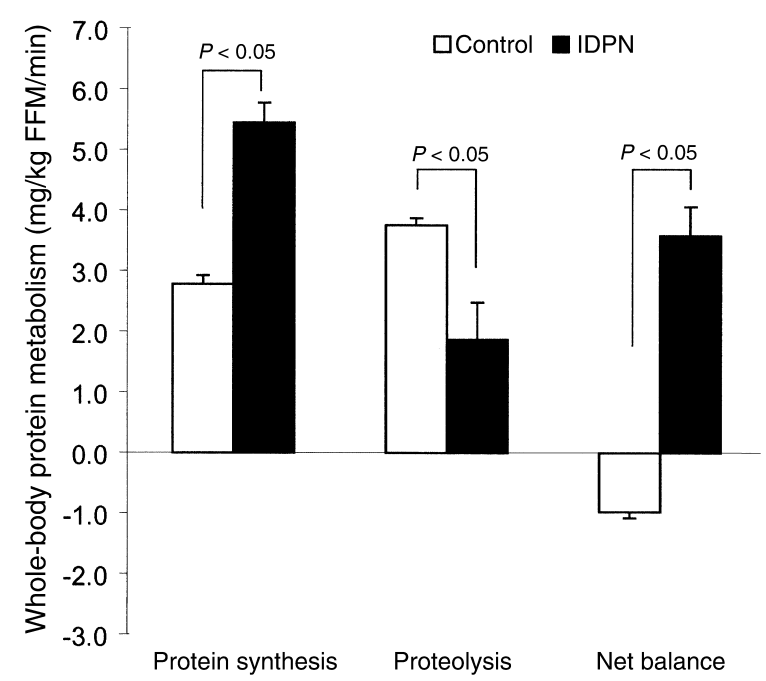

Figure 5

Whole-body protein components during HD, comparing control (white bars) and IDPN (black bars). Units are in milligrams per kilogram of FFM per minute. Significant differences were observed for all components of whole-body protein homeostasis during this period. There were no differences during predialysis or postdialysis periods (refer to Table 3 ). 
always successful in this patient population (30). Other forms of nutritional intervention have also been proposed, including oral feeding, tube feeding, and parenteral nutritional supplementation. Among these interventions, provision of nutrients during the HD procedure (i.e., IDPN) has been shown to be a safe and convenient approach. However, because of the cost and regulatory concerns, many of these studies focusing on IDPN involved a small number of patients for a limited period of time, and the results have not been consistent $(12,13)$. Also, these studies have been limited in terms of providing information about the metabolic consequences of this treatment modality. Most of the information on the metabolic effects of IDPN is based on indirect measures of protein metabolism, mainly biochemical markers of nutritional status. As a result, there is substantial reluctance to use this potentially beneficial treatment.

To explore this issue, we used methods to directly measure specific components of protein and energy metabolism in CHD patients following administration of IDPN. Based on these measurements, important mechanistic information could be inferred. Most importantly, net whole-body protein accretion improved substantially during IDPN administration, in contrast with net catabolism during regular $\mathrm{HD}$, changing the overall net protein balance from negative (loss) to positive (gain). The clinical relevance of this gain can be appreciated when one calculates that during the 3.5 hours when IDPN was being infused during HD, approximately $51.5 \mathrm{~g}$ of whole-body protein were anabolized compared with an essentially catabolic process in the absence of IDPN. If the body's FFM is $73 \%$ water, this accounts for accretion of an additional $191 \mathrm{~g}$ of FFM gain due to the IDPN treatment. These findings clearly support the premise that the infused AAs are retained and used by these patients (31).
A notable feature of the techniques used in this study is that we were able to separately evaluate skeletal muscle protein metabolism. Indeed, IDPN administration reversed net forearm protein balance from a negative (muscle breakdown) to a highly positive (muscle accretion) value during HD. This suggests that IDPN provides adequate AAs to replenish the intracellular pool sufficiently to increase muscle protein synthesis during a state where significant amounts of AAs are being lost into the dialysate, inducing net protein anabolism both for visceral and somatic protein stores (11).

Studies examining nutrient supplementation under many different conditions have demonstrated that muscle protein stores are not determined by nutrient intake alone. Insulin action also plays an important role controlling nutrient deposition. Insulin decreases circulating concentrations of glucose, AAs, and lipids, promotes inward cellular transport of glucose and AAs, enhances glycogen synthesis, stimulates adipose cells to synthesize and store lipids, and promotes protein accretion (32). Specifically, circulating insulin influences carbohydrate homeostasis by altering muscle glucose transport $(33,34)$ and use $(35)$ and regulates protein dynamics by stimulating AA transport, promoting whole-body and muscle protein synthesis, and inhibiting proteolysis (32). These effects are amplified when AA availability is increased simultaneously with insulin (32). In the present study, insulin concentration increased by approximately fourfold when IDPN was administered. In overnight fasted normal subjects, approximately sevenfold insulin elevation, with nearbasal AA concentrations maintained, did not increase whole-body protein synthesis, but decreased proteolysis by $25 \%$ from basal concentrations (32). Increased insulin alone decreased protein breakdown by $16 \%$. Increased insulin concentration and ample AA availability due to IDPN in the present study decreased

Table 4

Components of energy metabolism and substrate oxidation

\begin{tabular}{|c|c|c|c|c|}
\hline & & Before HD & During HD & After HD \\
\hline Energy expenditure (kcal/kg FFM/h) & $\begin{array}{l}\text { CTL } \\
\text { IDPN }\end{array}$ & $\begin{array}{l}1.20 \pm 0.05 \\
1.19 \pm 0.04\end{array}$ & $\begin{array}{l}1.29 \pm 0.05 \\
1.34 \pm 0.06\end{array}$ & $\begin{array}{l}1.39 \pm 0.05 \\
1.45 \pm 0.07\end{array}$ \\
\hline Respiratory quotient & $\begin{array}{l}C T L \\
\text { IDPN }\end{array}$ & $\begin{array}{l}0.85 \pm 0.02 \\
0.87 \pm 0.02\end{array}$ & $\begin{array}{l}0.84 \pm 0.01 \\
0.83 \pm 0.01\end{array}$ & $\begin{array}{l}0.79 \pm 0.01 \\
0.81 \pm 0.01\end{array}$ \\
\hline AA oxidation (mg/kg FFM/min) & $\begin{array}{l}C T L \\
\text { IDPN }\end{array}$ & $\begin{array}{l}0.54 \pm 0.10 \\
0.57 \pm 0.07\end{array}$ & $\begin{array}{l}0.52 \pm 0.06 \\
0.87 \pm 0.12^{\mathrm{A}}\end{array}$ & $\begin{array}{l}0.65 \pm 0.13 \\
0.89 \pm 0.06\end{array}$ \\
\hline Carbohydrate oxidation (mg/kg FFM/min) & $\begin{array}{l}C T L \\
\text { IDPN }\end{array}$ & $\begin{array}{l}2.61 \pm 0.31 \\
2.89 \pm 0.33\end{array}$ & $\begin{array}{l}2.50 \pm 0.22 \\
2.56 \pm 0.44\end{array}$ & $\begin{array}{l}1.53 \pm 0.31 \\
2.17 \pm 0.44\end{array}$ \\
\hline Lipid oxidation (mg/kg FFM/min) & $\begin{array}{l}C T L \\
\text { IDPN }\end{array}$ & $\begin{array}{l}0.96 \pm 0.13 \\
0.83 \pm 0.18\end{array}$ & $\begin{array}{l}1.15 \pm 0.09 \\
1.23 \pm 0.11\end{array}$ & $\begin{array}{l}1.75 \pm 0.14 \\
1.58 \pm 0.18\end{array}$ \\
\hline Energy balance (kcal/kg FFM/h) & $\begin{array}{l}\text { CTL } \\
\text { IDPN }\end{array}$ & $\begin{array}{l}-1.20 \pm 0.05 \\
-1.19 \pm 0.04\end{array}$ & $\begin{aligned}-1.29 & \pm 0.05 \\
2.16 & \pm 0.06^{\mathrm{A}}\end{aligned}$ & $\begin{array}{l}-1.39 \pm 0.05 \\
-1.45 \pm 0.07\end{array}$ \\
\hline AA balance (mg/kg FFM/h) & $\begin{array}{l}\text { CTL } \\
\text { IDPN }\end{array}$ & $\begin{array}{l}-0.54 \pm 0.10 \\
-0.57 \pm 0.07\end{array}$ & $\begin{aligned}-0.52 & \pm 0.06 \\
2.63 & \pm 0.12^{\mathrm{A}}\end{aligned}$ & $\begin{array}{l}-0.65 \pm 0.13 \\
-0.89 \pm 0.06\end{array}$ \\
\hline Carbohydrate balance (mg/kg FFM/h) & $\begin{array}{l}\text { CTL } \\
\text { IDPN }\end{array}$ & $\begin{array}{l}-2.61 \pm 0.31 \\
-2.89 \pm 0.33\end{array}$ & $\begin{aligned}-2.50 & \pm 0.22 \\
3.27 & \pm 0.44^{\mathrm{A}}\end{aligned}$ & $\begin{array}{l}-1.53 \pm 0.31 \\
-2.17 \pm 0.44\end{array}$ \\
\hline Lipid balance (mg/kg FFM/h) & $\begin{array}{l}C T L \\
\text { IDPN }\end{array}$ & $\begin{array}{l}-0.96 \pm 0.13 \\
-0.83 \pm 0.18\end{array}$ & $\begin{aligned}-1.15 & \pm 0.09 \\
1.10 & \pm 0.11^{\mathrm{A}}\end{aligned}$ & $\begin{array}{l}-1.75 \pm 0.14 \\
-1.58 \pm 0.18\end{array}$ \\
\hline
\end{tabular}

Values reported are the mean \pm SEM. ${ }^{A}$ Significant difference between control and IDPN $(P<0.05)$. 
whole-body proteolysis by $50 \%$, suggesting that the effects are likely the result of both increased AA availability and increased insulin action.

An interesting observation in this study was that the anabolic effects of IDPN administration did not carry over to the post-HD phase. Forearm AA concentrations, forearm AA uptake, and both protein synthesis and proteolysis returned toward baseline levels in the phase shortly after IDPN was discontinued. This was despite continued elevations in plasma insulin and forearm glucose uptake. This suggests that to accumulate the beneficial effects of this mode of nutritional supplementation repetitive administration might be needed. Clearly, long-term studies are required to examine the prolonged influence of these metabolic responses.

An important aspect of this study is that the population studied herein consisted of CHD patients who appeared to be adequately nourished and stable. Furthermore, they were nondiabetic, not profoundly anemic, optimally dialyzed, and free of any acute inflammatory state. Indeed, basal states of protein kinetics, as well as the response to nutritional supplementation, were similar to those of previously published values of healthy subjects from our laboratory $(36,37)$. This finding is in line with earlier studies showing that stable chronic renal failure patients adjust their protein homeostasis in response to decreased dietary protein intake (38). Clearly, the extent of the metabolic response that was observed in this study may be different in other subgroups of CHD patients. Therefore, further studies are needed to elucidate the differential effects of IDPN in CHD patients who may present with different metabolic abnormalities, such as metabolic acidosis, malnutrition, and patients with signs of acute or chronic inflammation. For example, the mean proteolysis increased approximately twofold with IDPN during HD, and the higher rate persisted in the post-HD phase, which calls for extra caution for patients who may have elevated rates of muscle proteolysis at baseline, such as metabolic acidosis and other catabolic condition. Also of note, we report only short-term effects of IDPN on a dialysis day, including only 2 hours of postdialysis observation. Based on our study, one can only speculate on the prolonged effects of IDPN. This should be considered in the context that the anabolic effects of IDPN were only evident during infusion and did not carry over to the immediate post-HD phase. Finally, while the techniques used in this study are associated with a very small margin of error; they are well-accepted and validated methods. In addition, we have used these techniques in several study populations and have found them to be reliable and reproducible $(36,39)$.

In summary, we have shown that administration of IPDN has a significant positive effect on protein and energy metabolism in stable CHD patients. IPDN promoted remarkable improvements in both net wholebody and skeletal muscle protein balance, culminating in reversal of a catabolic state and resulting in net protein accretion. Further research is needed to evaluate the metabolic effects of IDPN in different subgroups of CHD patients, as well as the long-term effects of this intervention.

\section{Acknowledgments}

The authors would like to express their appreciation to the patients and staff of Vanderbilt University Medical Center, Outpatient Dialysis Unit, for their participation in the study. This study is supported in part by NIH grant RO1-45604, Food and Drug Administration grant 000943, the Satellite Health Extramural Grant Program, Clinical Nutrition Research Unit grant DK-26657, GCRC grant RR 00095, Diabetes Research and Training Center grant DK-20593. L.B. Pupim is partly supported by the Master of Science in Clinical Investigation Program at Vanderbilt University Medical Center. The excellent technical assistance of Jennifer Gresham, Suzan Vaughan, Janice Harvell, Mu Zheng, Wanda Snead, and the nursing staff at the GCRC is appreciated.

1. USRDS. 1999. Excerpts from United States Renal Data System 1999 Annual Data Report. Am. J. Kidney Dis. 34(Suppl.):S1-S176.

2. Ikizler, T.A., Wingard, R.L., and Hakim, R.M. 1995. Interventions to treat malnutrition in dialysis patients: the role of the dose of dialysis, intradialytic parenteral nutrition, and growth hormone. Am. J. Kidney Dis. 26:256-265.

3. Hakim, R.M., and Levin, N. 1993. Malnutrition in hemodialysis patients. Am. J. Kidney Dis. 21:125-137.

4. Ikizler, T.A., Flakoll, P.J., Parker, R.A., and Hakim, R.M. 1994. Amino acid and albumin losses during hemodialysis. Kidney Int. 46:830-837.

5. Ikizler, T.A., et al. 1996. Increased energy expenditure in hemodialysis patients. J. Am. Soc. Nephrol. 7:2646-2653.

6. Ikizler, T.A., Greene, J., Wingard, R.L., Parker, R.A., and Hakim, R.M. 1995. Spontaneous dietary protein intake during progression of chronic renal failure. J. Am. Soc. Nephrol. 6:1386-1391.

7. Ikizler, T.A., Greene, J.H., Wingard, R.L., and Hakim, R.M. 1996. Nitrogen balance in hospitalized chronic hemodialysis patients. Kidney Int. Suppl. 57. 50:S53-S56.

8. Kopple, J.D. 2001. National kidney foundation K/DOQI clinical practice guidelines for nutrition in chronic renal failure. Am. J. Kidney Dis. 37(Suppl.):S66-S70.

9. Ikizler, T.A., et al. 2002. Hemodialysis stimulates muscle and whole body protein loss and alters substrate oxidation. Am. J. Physiol. Endocrinol. Metab. 282:E107-E116.

10. Lim, V.S., Bier, D.M., Flanigan, M.J., and Sum-Ping, S.T. 1993. The effect of hemodialysis on protein metabolism: a leucine kinetic study. J. Clin. Invest. 91:2429-2436.

11. Chertow, G.M., Ling, J., Lew, N.L., Lazarus, J.M., and Lowrie, E.G. 1994. The association of intradialytic parenteral nutrition with survival in hemodialysis patients. Am. J. Kidney Dis. 24:912-920.

12. Mortelmans, A.K., et al. 1999. Intradialytic parenteral nutrition in malnourished hemodialysis patients: A prospective long-term study. JPEN J. Parenter. Enterol. Nutr. 23:90-95.

13. Cranford, W. 1998. Effectiveness of IDPN therapy measured by hospitalizations and length of stay. Nephrol. News Issues. 12:33-39.

14. Pupim, L.B., Kent, P., and Hakim, R. 1999. The potential of intradialytic parenteral nutrition: a review. Miner. Electrolyte Metab. 25:317-323.

15. Kopple, J.D., Foulks, C.J., Piraino, B., Beto, J.A., and Goldstein, J. 1996. National Kidney Foundation position paper on proposed health care financing administration guidelines for reimbursement of enteral and parenteral nutrition. J. Ren. Nutr. 6:45-47.

16. Goldstein, D.S., Feuerstein, G., Izzo, J.L., Jr., Kopin, I.J., and Keiser, H.R. 1981. Validity and reliability of liquid chromatography with electrochemical detection for measuring plasma levels of norepinephrine and epinephrine in man. Life Sci. 28:467-475.

17. Morgan, C.R., and Lazarow, A. 1963. Immunoassay of insulin: two antibody system. Plasma insulin levels of normal, subdiabetic, and diabetic rats. Diabetes. 12:115-126.

18. Heinrikson, R.I., and Meredith, S.C. 1984. Amino acid analysis by 
reverse-phase high pressure liquid chromatography: Precolumn derivatization with phenylisothiocyanate. Anal. Biochem. 136:65-74.

19. Nissen, S.L., Van Huysen, C., and Haymond, M.W. 1982. Measurement of branched-chain $\alpha$-ketoacids in plasma by high performance liquid chromatography. J. Chromatogr. 232:170-175.

20. Schwenk, W.F., Berg, P.J., Beaufrere, B., Miles, J.M., and Haymond, M.W 1984. Use of $\mathrm{t}$-butyldimethylsilylation in the gas chromatographic/mass spectrometric analysis of physiologic compounds found in plasma using electron-impact ionization. Anal. Biochem. 141:101-109.

21. Scrimgeour, C.M., and Rennie, M.J. 1988. Automated measurement of the concentration and ${ }^{13} \mathrm{C}$ enrichment of carbon dioxide in breath and blood samples using the Finnigan MAT breath gas analysis system. Biomed. Environ. Mass Spectrom. 15:365-367.

22. Gelfand, R.A., and Barrett, E.J. 1987. Effect of physiologic hyperinsulinemia on skeletal muscle protein synthesis and breakdown in man. J. Clin. Invest. 80:1-6.

23. Wolfe, R.R. 1992. Radioactive and stable isotope tracers in biomedicine: principles and practice of kinetic analysis. Wiley-Liss. New York, New York, USA 283-316.

24. Allsop, J.R., Wolfe, R.R., and Burke, J.F. 1978. Tracer priming the bicarbonate pool. J. Appl. Physiol. 45:137-139.

25. Garlick, P.J., et al. 1987. Rates of nutrient utilization in man measured by combined respiratory gas analysis and stable isotopic labeling: effect of food intake. Hum. Nutr. Clin. Nutr. 41:177-191.

26. Jequier, E., Acheson, K., and Schutz, Y. 1987. Assessment of energy expenditure and fuel utilization in man. Annu. Rev. Nutr. 7:187-208.

27. Lazarus, M.J. 1993. Nutrition in hemodialysis patients. Am. J. Kidney. Dis. 21:99-105.

28. Wolfson, M., Strong, C.J., Minturn, R.D., Gray, D.K., and Kopple, J.D. 1984. Nutritional status and lymphocyte function in maintenance hemodialysis patients. Am. J. Clin. Nutr. 37:547-555.

29. Kaysen, G.A., Stevenson, F.T., and Depner, T.A. 1997. Determinants of albumin concentration in hemodialysis patients. Am. J. Kidney Dis. 29:658-668.

30. Dwyer, J.T., et al. 1998. The hemodialysis pilot study: nutrition program and participant characteristics at baseline. The HEMO Study Group. J. Ren. Nutr. 8:11-21.

31. Wolfson, M., Jones, M.R., and Kopple, J.D. 1982. Amino acid losses during hemodialysis with infusion of amino acids and glucose. Kidney Int 21:500-506.

32. Flakoll, P.J., Carlson, M., and Cherrington, A.D. 2000. Physiologic action of insulin. In Diabetes mellitus. 2nd edition. Lippincott Williams \& Wilkins Publishers. Philadelphia, Pennsylvania, USA. 148-161.

33. Douen, A.G., et al. 1990. Exercise induces recruitment of the "insulinresponsive glucose transporter." Evidence for distinct intracellular insulin- and exercise-recruitable transporter pools in skeletal muscle. J. Biol. Chem. 265:13427-13430.

34. Goodyear, L.J., et al. 1990. Contractile activity increases plasma membrane glucose transporters in absence of insulin. Am. J. Physiol. 258:E667-E672.

35. Wasserman, D.H., et al. 1991. Interaction of exercise and insulin action in humans. Am. J. Physiol. 260:E37-E45.

36. Levenhagen, D.K., et al. 2001. Postexercise nutrient intake timing in humans is critical to recovery of leg glucose and protein homeostasis. Am. J. Physiol. Endocrinol. Metab. 280:E982-E993.

37. Borel, M.J., et al. 1998. Alterations in basal nutrient metabolism increase resting energy expenditure in sickle cell disease. Am. J. Physiol. 274:E357-E364.

38. Goodship, T.H.J., et al. 1990. Adaptation to low-protein diets in renal failure: leucine turnover and nitrogen balance. J. Am. Soc. Nephrol. 1:66-75.

39. Flakoll, P.J., Wentzel, L.S., and Hyman, S.A. 1995. Protein and glucose metabolism during isolated closed-head injury. Am. J. Physiol. 269:E636-E641. 